\title{
Utility of risk-weighted surgical-pathological factors in early-stage cervical cancer
}

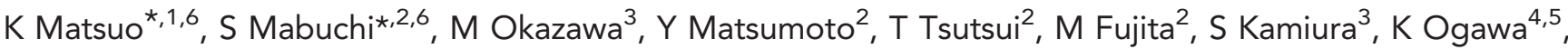 \\ C P Morrow ${ }^{1}$ and T Kimura ${ }^{2}$
}

${ }^{1}$ Department of Obstetrics and Gynecology, Division of Gynecologic Oncology, Los Angeles County Medical Center, University of Southern California, 2020 Zonal Avenue, Los Angeles, CA 90031, USA; ${ }^{2}$ Department of Obstetrics and Gynecology, Osaka University Graduate School of Medicine, 2-2 Yamadaoka, Suita, Osaka 565-0871, Japan; ${ }^{3}$ Department of Gynecology, Osaka Medical Center for Cancer and Cardiovascular Diseases, 1-3-3 Nakamichi, Higashinari-ku, Osaka 537-8511, Japan; ${ }^{4}$ Department of Radiation Oncology, Osaka University Graduate School of Medicine, 2-2 Yamadaoka, Suita, Osaka 565-0871, Japan and ${ }^{5}$ Department of Radiation Oncology, Osaka Medical Center for Cancer and Cardiovascular Diseases, 1-3-3 Nakamichi, Higashinari-ku, Osaka 537-8511, Japan

Background: Surgical-pathological risk factors were evaluated by weighting the magnitude of significance of multiple risk factors correlating to survival and treatment response in cervical cancer.

Methods: Multivariate analysis was performed for survival outcomes entering seven pathological factors obtained from 540 radical hysterectomy specimens in stage IA2-IIB cervical cancer cases. Hazard ratio (HR) in each risk factor was determined, and the sum of HR scores for the corresponding risk factors was determined per case. Survival curves and postoperative treatment response (concurrent chemoradiotherapy (CCRT) vs radiotherapy alone) were evaluated based on the extent of HR-weighted scores.

Results: Hazard ratios for risk factors relating to disease-free survival (DFS) was: lympho-vascular space invasion 3.95, nodal metastasis 3.88, adenocarcinoma 3.40, large tumour 2.36, positive margin 1.99, deep stromal invasion 1.29, and parametria invasion 1.21. The HR-weighted scoring method showed a high predictive value for recurrence (area-under-curve $0.836, P<0.001$ ). Hazard ratio-weighted scores were negatively correlated to DFS, and the cases with score $\geqslant 12.5$ showed 5-year DFS rate of $23.8 \%$. Tumours with larger score offset the benefits of CCRT over radiotherapy alone for postoperative adjuvant treatment $(P<0.001)$.

Conclusion: Surgical-pathological risk factors provide valuable information for survival and management of early-stage cervical cancer when number and significance of risks are weighted.

Cervical cancer remains the most common gynaecologic malignancy in the world (Jemal et al, 2011). In 2008, nearly 530000 women were diagnosed with cervical cancer and $\sim 275000$ died from this disease, which makes it the most deadly gynaecologic malignancy globally (Jemal et al, 2011). Cervical cancer is clinically staged, and the majority of early-stage cervical cancer patients who underwent surgical treatment with radical hysterectomy will receive postoperative adjuvant therapy based on the results of surgical-pathological risk factors (Waggoner, 2003).
Histologically, surgical-pathological risk factors were classified into low-, intermediate-, and high-risk (Delgado et al, 1990; Sedlis et al, 1999; Peters et al, 2000). Positive lymph nodes, positive surgical margins, and parametrial involvement are classified as high-risk factors (Peters et al, 2000), while large tumour size, lymphovascular space invasion (LVSI), and deep cervical stromal invasion are categorised as intermediate-risk factors (Delgado et al, 1990; Sedlis et al, 1999). These risk factors are not only valuable to identify the patients who require postoperative adjuvant therapy,

\footnotetext{
*Correspondence: Dr K Matsuo; E-mail: koji.matsuo@gmail.com or Dr S Mabuchi; E-mail: smabuchi@gyne.med.osaka-u.ac.jp

${ }^{6}$ These authors contributed equally to this study.
} 
but are also important determinants of patient survival outcomes (Havrilesky et al, 2004). One of the limitations of this traditional risk factor classification is that the impact of multiple risk factors on survival outcomes remains not yet completely elucidated (Monk et al, 2005; Rotman et al, 2006). Tumours may exhibit more than two risk factors with multiple high-risk factors or with combined intermediate- and high-risk factors. Therefore, profiling the significance of multiple risk factors quantitatively (by number of risk factors) and qualitatively (by magnitude of significance for survival) will help clinicians to guide the understanding of postoperative management of patients.

The aim of the study was to evaluate the survival outcomes of surgically treated early-stage cervical cancer patients by surgicalpathological risk factors examining the effects of number and hazard ratio (HR) for survival. Its utility of scoring was further examined to assess the treatment response of postoperative adjuvant therapy.

\section{MATERIAL AND METHODS}

Clinical information. After the approval from Institutional Review Board was obtained at Osaka University Hospital and Osaka Medical Centre for Cancer and Cardiovascular Diseases, the institutional database from our Tumour Registry for cervical cancer was utilised to identify the cases. The inclusion criterion was having undergone radical hysterectomy and bilateral pelvic lymphadenectomy for stage IA2-IIB cervical cancer from January 1998 to December 2008. Cases with adenoid basal carcinoma, adenoid cystic carcinoma, glassy cell carcinoma, undifferentiated carcinoma, and small cell carcinoma were not included in the study. In our institutions, the histological evaluation of surgical specimens was performed by two independent gynaecologic pathologists based on the World Health Organisation (WHO (2002)) staging system for tumours of the uterine cervix, and histology, LVSI, tumour size (largest diameter), marginal status (positive or negative for malignancy), parametrial involvement, deep stromal invasion $(>50 \%)$, and lymph nodal metastasis were routinely recorded. In our standard practice, cervical cancer was clinically staged according to the International Federation of Gynaecology and Obstetrics (FIGO) staging criteria. The initial work-up at the diagnosis consisted of: history taking for medicosurgical complication; complete physical examination; a complete blood count; chemistry panels; chest X-rays; computed tomography (CT) scans of the abdomen and pelvis; pelvic magnetic resonance imaging; and optional intravenous pyelography, cystoscopy, and recto-sigmoidoscopy. Para-aortic lymph nodes (PALN) were preoperatively evaluated with a CT scan of the abdomen as part of the routine initial evaluation. Subsets of the patients evaluated in the study were within the context of previous clinical studies (Mabuchi et al, 2009, 2011a, b; Okazawa et al, 2012).

\section{Treatments}

Surgery. All patients were treated with type III radical hysterectomy and pelvic lymphadenectomy, as reported previously (Mabuchi et al, 2011a). Lymphadenectomy included complete bilateral pelvic lymphadenectomy aiming the removal of all of external iliac, internal iliac, common iliac, obturator, suprainguinal, and presacral lymph nodes systematically. Intra-operative assessment of the PALN was routinely performed by manual palpation. When PALN metastasis was preoperatively or intraoperatively suspected, nodal resection was performed for histological confirmation. Cases with histologically confirmed PALN metastasis were not included in the study.
Postoperative radiotherapy. Postoperative radiotherapy is indicated when patient's pathological report displays any of the following 'high-risk' prognostic factors: parametrial invasion, pelvic lymph node metastasis, or a positive surgical margin, or one of the following 'intermediate-risk' prognostic factors: deep stromal invasion, LVSI, or a large tumour (over $4 \mathrm{~cm}$ in diameter). A group of cases with early-stage cervical cancer without any of the above-mentioned risk factors and who, therefore, did not receive postoperative adjuvant therapy was categorised as low-risk group. These low-, intermediate-, and high-risk factors were termed as 'traditional risk factor' in the study.

In our standard radiotherapy, patients receive external beam pelvic radiotherapy plus concurrent chemoradiotherapy (CCRT), as reported previously (Mabuchi et al, 2009, 2011a, b). However, historically, patients who received a care before January 1999 in our practice were treated with pelvic radiotherapy alone. Patients who declined CCRT also received radiotherapy alone. Postoperative whole-pelvic radiotherapy was performed using 10 megavolt (MV) X-rays delivered from a linear accelerator using the antero-posterior parallel opposing technique. The superior margin of the external radiation field was located at the top of the fifth lumber vertebra, and the inferior border of the obturator foramen was used as the distal margin. Laterally, the field extended $2 \mathrm{~cm}$ beyond the lateral margin of the bony pelvic wall. We used multileaf collimators to block the upper and lower corners of the radiation field. The external irradiation was delivered to the whole pelvis at $2 \mathrm{~Gy}$ per fraction in five fractions per week for a total of 25 fractions (total dose, $50 \mathrm{~Gy}$ ).

Among patients for whom CCRT was initially planned, 26 patients whose pathological reports revealed multiple pelvic node metastases were treated with extended field radiotherapy (EFRT) without CCRT, as reported previously (Mabuchi et al, 2011b). Postoperative EFRT was also administered to the patients via 10 MV X-rays delivered from a linear accelerator using the anteroposterior parallel opposing technique. The radiation field encompassed the pelvic and the PALN drainage area. The superior margin of the PALN area was located at the bottom of the T12 vertebral body, and the inferior margin was located at the inferior border of the obturator foramen. The lateral margin was located at $1.5-2 \mathrm{~cm}$ lateral to the widest point of the bony pelvis. The external irradiation was delivered to the EFRT fields for a total of $45 \mathrm{~Gy}$ in 25 fractions and to the whole pelvis at $1.8 \mathrm{~Gy}$ per fraction for a total of 28 fractions (total dose, $50.4 \mathrm{~Gy}$ ).

Concurrent chemoradiotherapy. In our institutions, nedaplatin is administered as the radiosensitising agent for patients with cervical cancer. Nedaplatin was given intravenously during the course of radiotherapy, as reported previously (Mabuchi et al, 2009; Mabuchi and Kimura, 2011; Mabuchi et al, 2011b).

Follow-up. The patients were followed regularly both by gynaecological oncologists and radiation oncologists after treatment, as described previously (Mabuchi et al, 2010, 2012). When recurrence was clinically or radiographically suspected, a biopsy was performed for confirmation whenever possible. The median follow-up duration was 5.0 years (range 0.5-5.1).

Statistical analysis. We first determined the statistical significance of surgical-pathological risk factors associated with survival outcomes both for disease-free survival (DFS) and for overall survival (OS). Then, three scoring methods were examined to evaluate the predictive value for recurrence or disease-related death in receiver-operator-characteristic curve analysis comparing areaunder-curve (AUC). The first scoring method recorded the crude number of risk factors per individual (Number method). For instance, if the patient had two risk factors, the score is recorded as 2 for the case. The remaining two methods were based 
on weighting the value of $\mathrm{HR}$ determined in multivariate analysis: (i) entering all surgical-pathological risk factors that showed statistical significance in univariate analysis (Risk-weighted method 1); (ii) and entering only those statistically significant surgical-pathological risk factors that were demonstrated in the conditional backward method (Risk-weighted method 2). For instance, if the patient has two risk factors (HR 3.2 for one risk factor and HR 2.4 for the other risk factor), the score will be $3.2+2.4=5.6$ for the case. In addition to these three methods, traditional risk factor method (low, intermediate, and high) and clinical staging method (IA2-IIB) were also examined for the predictive value for survival outcomes. Among the three methods proposed in the current study, the scoring method with the highest AUC for survival events was chosen for the further analysis. To implicate the utility of scoring method in clinical practice, the survival outcomes, as well as treatment response for postoperative adjuvant therapy, were examined based on the scoring results. Survival curves were constructed using the Kaplan-Meier method, and the significance of survival differences was determined with the log-rank test in univariate analysis. For multivariate analysis, Cox proportional-hazards regression test was performed to assess the ability of the prognostic factors to predict survival outcomes expressed as HR and 95\% confidence interval (CI). Fisher's exact test was used for categorical variables expressed with odds ratio (OR) with 95\% CI. Ordinal variables were examined for the statistical significance using Spearman's correlation coefficient. All statistical analyses were two-tailed, and $P$-values of $<0.05$ were considered statistically significant. Statistical Package for Social Scientists software (SPSS, version 12.0, IL, USA) was used for all analyses.

\section{RESULTS}

Patient characteristics. There were 540 cases evaluated for the analysis. The clinico-pathological demographics of patients are shown in Table 1. In our study, LVSI (58.3\%) and deep stromal invasion (49.3\%) were the common risk factors, and positive margins were relatively infrequent. The surgical-pathological risk factors were correlated for statistical significance (Supplementary Table S1). All the traditional risk factors had either significant or marginal correlations with each other. Among the significant correlations, LVSI and pelvic nodal metastasis showed the strongest correlation (41.9\% vs $0.4 \%$, OR 162, 95\% CI 22.3-1167, $P<0.001)$. None of low-risk factor patients (43.1\%) received postoperative therapy. Among intermediate- or high-risk patients $(n=307), 188$ (61.2\%) patients received CCRT and the remaining $119(38.8 \%)$ received radiotherapy alone. Ninety-seven (18.0\%) cases developed recurrence and $69(12.8 \%)$ cases died of disease.

Surgical-pathological risk factors and survival outcomes. Seven pathological factors were then correlated to DFS and OS (Tables 2 and 3). Univariate analysis identified all of these seven pathological factors as statistically significant variables for both DFS and OS. In multivariate analysis where all seven pathological factors were entered, the magnitudes of significance for DFS were in the following order: LVSI (HR 3.95), nodal metastasis (HR 3.88), nonsquamous histology (HR 3.40), large tumour (HR 2.36), positive marginal status (HR 1.99), deep stromal invasion (HR 1.29), and parametrial invasion (HR 1.21) (Multivariate 1 method in Table 2). Multivariate analysis in conditional backward method showed majority of variables to be significant for DFS (Multivariate 2 in Table 2).

Similarly, 5-year OS rates were examined (Table 3): in multivariate analysis where all seven pathological factors were entered, the magnitudes of significance for OS were in the following order: LVSI (HR 6.02), nodal metastasis (HR 3.61),
Table 1. Patient demographics

\begin{tabular}{|l|c|}
\hline Subjects & $\mathbf{N}=\mathbf{5 4 0}$ \\
\hline Age & $47( \pm 11.2)$ \\
\hline Clinical stage $^{\text {b }}$ & \\
\hline IA2 & $35(6.5 \%)$ \\
IB1 & $312(57.8 \%)$ \\
IB2 & $48(8.9 \%)$ \\
IIA & $65(12.0 \%)$ \\
IIB & $80(14.8 \%)$
\end{tabular}

\begin{tabular}{|l|c|}
\hline Histology & $377(69.8 \%)$ \\
\hline Squamous & $143(26.5 \%)$ \\
Adenocarcinoma & $20(3.7 \%)$ \\
Adenosquamous &
\end{tabular}

\section{High-risk factors}

\begin{tabular}{l|c} 
Lymph node metastasis & $133(24.6 \%)$ \\
Parametria invasion & $103(19.1 \%)$ \\
Positive marginal status & $19(3.5 \%)$
\end{tabular}

Intermediate-risk factors

\begin{tabular}{l|l} 
LVSI & $315(58.3 \%)$ \\
Deep stromal invasion & $266(49.3 \%)$ \\
Large tumour $(>4 \mathrm{~cm})^{\mathrm{a}}$ & $100(18.5 \%)$
\end{tabular}

Postoperative adjuvant therapy

\begin{tabular}{l|l} 
None & $233(43.1 \%)$ \\
CCRT & $188(34.8 \%)$ \\
RT alone & $119(22.0 \%)$
\end{tabular}

\begin{tabular}{|l|r|}
\hline \multicolumn{2}{|l|}{ Pathological risk group } \\
\hline Low & $233(43.1 \%)$ \\
Intermediate & $130(24.1 \%)$ \\
High & $177(32.8 \%)$ \\
\hline Abbreviations: CCRT = concurrent chemoradiotherapy; LVSI = lymphovascular space \\
invasion; RT= radiotherapy. Mean $( \pm$ s.d.), median (range), or number (\%) is shown. \\
a Median tumour size is $3.0 \mathrm{~cm}($ range $0.5-8.0 \mathrm{~cm})$. \\
bAs per the International Federation of Gynaecology and Obstetrics (FIGO) staging criteria. \\
\hline
\end{tabular}

non-squamous histology (HR 3.48), positive marginal status (HR 2.09), large tumour (HR 1.31), deep stromal invasion (HR 1.30), and parametrial invasion (HR 1.02) (Multivariate 1 method in Table 3). In multivariate analysis using conditional backward method, LVSI (HR 7.28), nodal metastasis (HR 3.91), non-squamous histology (HR 3.38) remained as the three strongest independent risk factors associated with OS (Multivariate 2 method in Table 3).

Comparison of surgical-pathological risk factor scoring methods. Three systemic methods of scoring utilising the results of survival analysis were compared (Table 4$)$. There were 425 (78.7\%) of cases that showed at least one risk factor. In Number method, the median number of risk factors per case was 2 . In Risk-weighted method 1, the mean value was 5.24 for DFS and 7.32 for OS, respectively. For Risk-weighted method 2, the mean value was 5.12 for DFS and 6.31 for OS, respectively. Frequencies of these three methods are shown in Supplementary Figure S1A-E. Areaunder-curve was examined for predictive value for recurrence or death due to disease using these three scoring methods (Table 4). All three methods showed considerably high predictive values for survival events (AUC $>0.8$ for all), and these values were higher than traditional pathological risk factor or clinical staging methods (both, AUC <0.8). Among the tested methods, Risk-weighted 


\begin{tabular}{|c|c|c|c|c|c|c|c|}
\hline & & \multicolumn{2}{|c|}{ Univariate } & \multicolumn{2}{|c|}{ Multivariate 1} & \multicolumn{2}{|c|}{ Multivariate 2} \\
\hline & Five-year (\%) & HR $(95 \% \mathrm{Cl})$ & $\boldsymbol{P}$-value & HR $(95 \% \mathrm{Cl})$ & $\boldsymbol{P}$-value & HR $(95 \% \mathrm{Cl})$ & $\boldsymbol{P}$-value \\
\hline Histology & & & 0.004 & & $<0.001$ & & $<0.001$ \\
\hline $\begin{array}{l}\mathrm{SCC} \\
\mathrm{AC} / \mathrm{AS}\end{array}$ & $\begin{array}{l}81.9 \% \\
72.0 \%\end{array}$ & $\begin{array}{c}1 \\
1.79(1.20-2.68)\end{array}$ & & $\begin{array}{c}1 \\
3.40(2.23-5.20)\end{array}$ & & $\begin{array}{c}1 \\
3.36(2.20-5.14)\end{array}$ & \\
\hline Lymph node metastasis & & & $<0.001$ & & $<0.001$ & & $<0.001$ \\
\hline $\begin{array}{l}\text { No } \\
\text { Yes }\end{array}$ & $\begin{array}{l}89.6 \% \\
49.4 \%\end{array}$ & $\begin{array}{c}1 \\
6.54(4.33-9.89)\end{array}$ & & $\begin{array}{c}1 \\
3.88(2.41-6.24)\end{array}$ & & $\begin{array}{c}1 \\
4.19(2.64-6.65)\end{array}$ & \\
\hline Parametria invasion & & & $<0.001$ & & 0.41 & & \\
\hline $\begin{array}{l}\text { No } \\
\text { Yes }\end{array}$ & $\begin{array}{l}84.1 \% \\
58.7 \%\end{array}$ & $\begin{array}{c}1 \\
3.30(2.20-4.95)\end{array}$ & & $\begin{array}{c}1 \\
1.21(0.77-1.92)\end{array}$ & & & \\
\hline LVSI & & & $<0.001$ & & $<0.001$ & & $<0.001$ \\
\hline $\begin{array}{l}\text { No } \\
\text { Yes }\end{array}$ & $\begin{array}{l}95.5 \% \\
67.9 \%\end{array}$ & $\begin{array}{c}1 \\
9.08(4.41-18.7)\end{array}$ & & $\begin{array}{c}1 \\
3.95(1.71-9.14)\end{array}$ & & $\begin{array}{c}1 \\
4.62(2.09-10.2)\end{array}$ & \\
\hline Deep stromal invasion & & & $<0.001$ & & 0.4 & & \\
\hline $\begin{array}{l}\text { No } \\
\text { Yes }\end{array}$ & $\begin{array}{l}91.1 \% \\
67.4 \%\end{array}$ & $\begin{array}{c}1 \\
4.47(2.73-7.30)\end{array}$ & & $\begin{array}{c}1 \\
1.29(0.71-2.35)\end{array}$ & & & \\
\hline Large tumour & & & $<0.001$ & & 0.06 & & 0.025 \\
\hline $\begin{array}{l}\text { No } \\
\text { Yes }\end{array}$ & $\begin{array}{l}82.9 \% \\
62.3 \%\end{array}$ & $\begin{array}{c}1 \\
2.76(1.82-4.20)\end{array}$ & & $\begin{array}{c}1 \\
2.36(0.98-2.36)\end{array}$ & & $\begin{array}{c}1 \\
1.64(1.06-2.52)\end{array}$ & \\
\hline $\begin{array}{l}\text { Abbreviations: } \mathrm{AC}=\text { adenoca } \\
5 \text {-yr }(\%)=5 \text {-year disease-free } \\
\text { univariate, log-rank test. }\end{array}$ & $\begin{array}{l}\mathrm{AS}=\text { adenosqu } \\
\text { te. Cox proport }\end{array}$ & $\begin{array}{l}\text { s; } 95 \% \mathrm{Cl}=95 \% \\
\text { hazards regressic }\end{array}$ & $\begin{array}{l}\text { e inten } \\
\text { multiva }\end{array}$ & $\begin{array}{l}\text { azard ratio; LVS } \\
h \text { all variables e }\end{array}$ & $\begin{array}{l}\text { ovascular } \\
\text { d multiv }\end{array}$ & $\begin{array}{l}\text { invasion; SCC = sq } \\
\text { conditional backwa }\end{array}$ & $\begin{array}{l}\text { s cell carci } \\
\text { thod). P-va }\end{array}$ \\
\hline
\end{tabular}

method 1 showed the highest predictive value for both recurrence (AUC 0.836) and death due to disease (AUC 0.837). Therefore, this method was used for the further analysis in the study.

Risk-weighted surgical-pathological score was positively correlated to traditional pathological risk factor (Figure 1A) and clinical stage (Figure 1B). Survival curves were constructed based on the extent of score values (Figures 1C and D). Five-year DFS rate were $96.6 \%, 93.2 \%, 84.1 \%, 73.1 \%, 53.3 \%$, and $23.8 \%$ for score $0,1.0-4.9$, $5.0-7.4,7.5-9.9,10.0-12.4$, and $\geqslant 12.5$, respectively $(P<0.001$, Figure 1C). Five-year OS rate were $100 \%, 94.9 \%, 88.9 \%, 79.0 \%$, $71.9 \%$, and $43.3 \%$ in these score groups, respectively $(P<0.001$, Figure 1C). Magnitude of statistical significance in risk-weighted surgical-pathological scoring method was larger than traditional risk factor method in DFS with wider range of survival rates among groups (log-rank value, 154.3 vs 78.5; 5-year DFS range, 23.8-96.6\% vs 58.5-94.4\%; Figures 1C vs E) and in OS (log-rank value, 119.2 vs 59.0; 5-year OS range, $43.3-100 \%$ vs $71.0-97.7 \%$; Figures 1D vs 1F). Similarly, magnitude of significance in riskweighted surgical-pathological scoring method was larger than clinical staging method both in DFS (log-rank value, 154.3 vs 82.5; 5-year DFS range, 23.8-96.6\% vs 53.9-89.7\%; Figures 1C vs G) and in OS (log-rank value, 119.2 vs 51.6; 5-year OS range, $43.3-100 \%$ vs 68.1-100\%; Figures 1D vs H). Number method showed similar results to the risk-weighted surgical-pathological methods (Supplementary Figures S2A-B).

Risk-weighted surgical-pathological scoring and treatment response. Clinical implications of risk-weighted surgicalpathological factor scoring were examined among patients that proceeded to receive postoperative adjuvant therapy $(n=307)$. Five-year DFS rate was evaluated between CCRT and radiotherapy
(RT) alone groups based on the scoring value (Figures 2A-F): score 0 , no patient received adjuvant therapy (Figure 2A); score 1.0-4.9, $100 \%$ vs $81.0 \%(P=0.025$, Figure $2 \mathrm{~B})$; score $5.0-7.4,91.4 \%$ vs $68.2 \% \quad(P=0.006$, Figure $2 \mathrm{C})$; score $7.5-9.9,82.4 \%$ vs $56.1 \%$ $(P=0.024$, Figure 2D); score $10-12.4,58.8 \%$ vs $46.2 \%(P=0.16$, Figure $2 \mathrm{E}$ ), and score $\geqslant 12.5,20.0 \%$ vs $25.6 \%(P=1.0$, Figure $2 \mathrm{~F})$. Risk-weighted surgical-pathological score was statistically significantly correlated with the magnitude of HR for CCRT in DFS (Spearman's $r=1.0, P<0.001$, Figure 2G), implying that higher scores in the method offset the clinical benefits of CCRT when compared with RT alone. Similar results were seen in OS although it did not reach statistical significance $(r=0.7, P=0.19$, Figure $2 \mathrm{H}$ ). This finding was not picked up by the traditional risk factor classification, and when the high-risk group patients were examined for DFS $(n=177)$, CCRT remained as the beneficial therapeutic modality when compared with RT alone (HR 0.43, $P=0.001$ ).

Multiple traditional risk factors and risk-weighted surgicalpathological scoring. Tumour spread and metastasis patterns were examined based on the number and extent of high- and intermediate-risk factors. Surgical-pathological risk factor array is shown in Table 5. There were 44 total patterns of tumour spread in cervical cancer, and $29(65.9 \%)$ patterns fell into high-risk groups in traditional risk classification. Of those, 12 (41.4\%) patterns representing $68(12.6 \%)$ patients demonstrated multiple high-risk factors, and $22(75.9 \%)$ showed a high-risk factor with $\geqslant 2$ intermediate-risk factors (148 patients, 27.4\%). Among the 15 (34.1\%) patterns included in the traditional intermediate-risk group, 8 (53.3\%) patterns accounted for 98 (18.1\%) patients that exhibited two or greater intermediate-risk factors. 
Table 3. Overall survival based on surgical-pathological factors

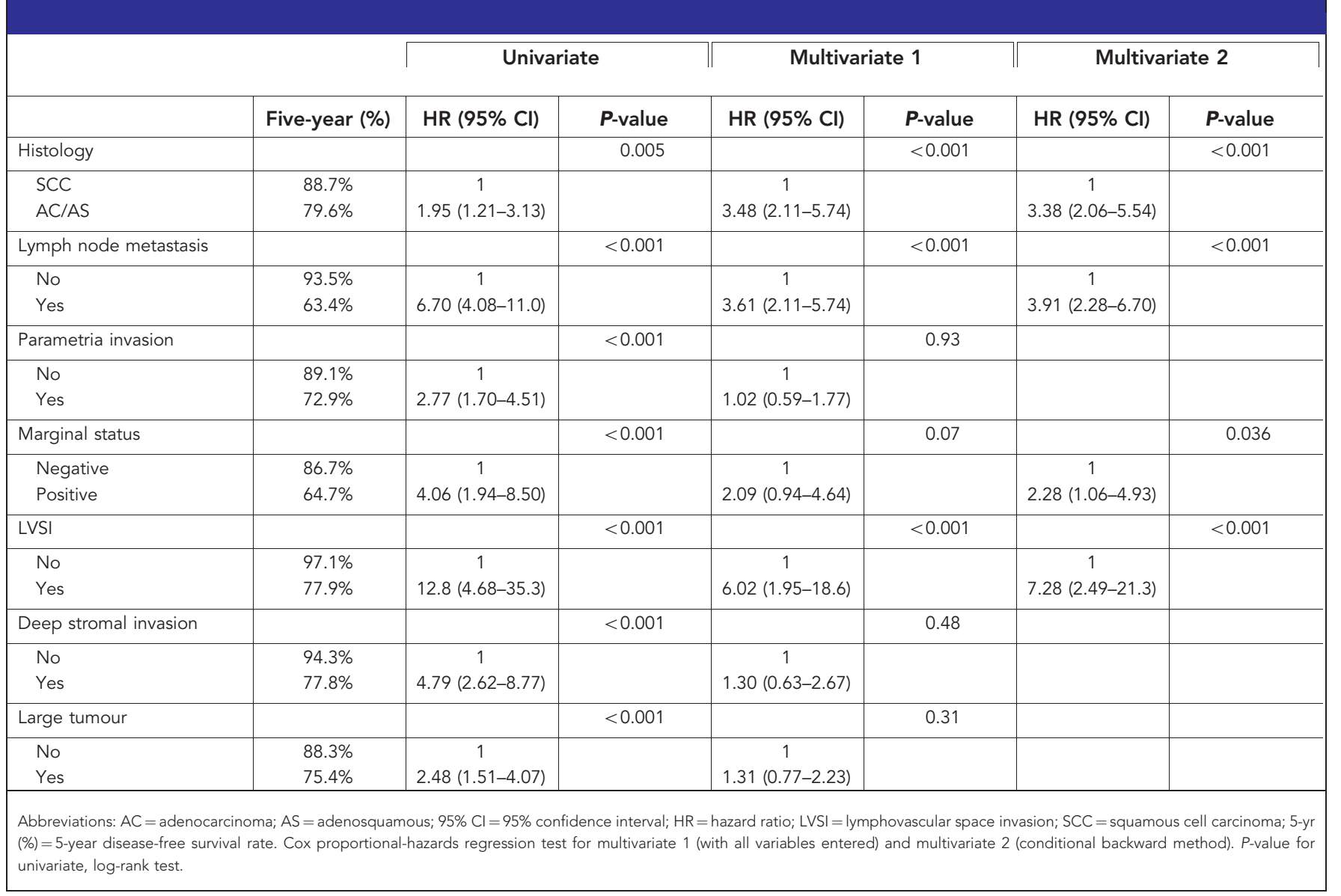

Table 4. Comparison of scoring methods for survival outcomes

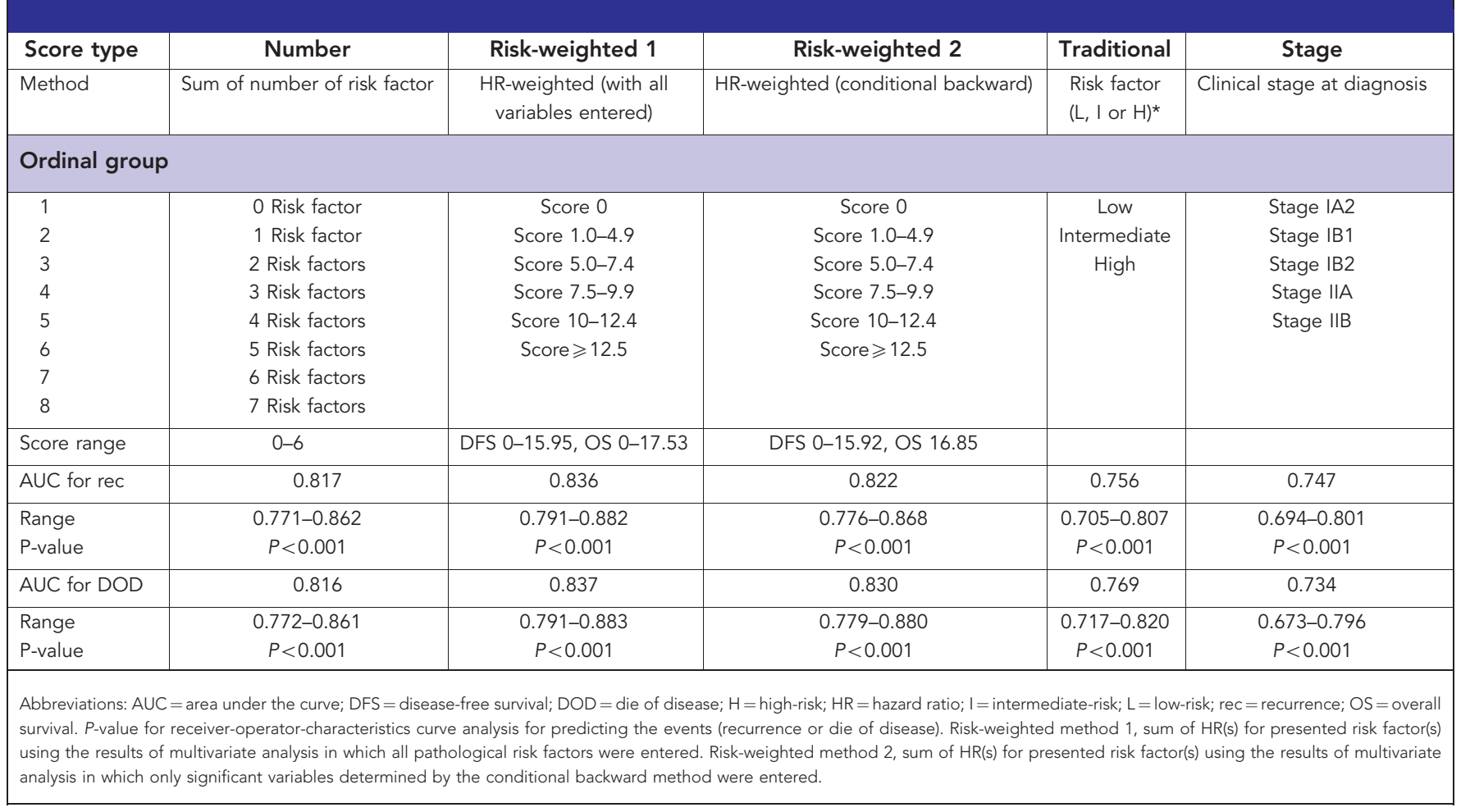


Among the 44 patterns of tumour spread, 18 (40.9\%) patterns showed risk-weighted surgical-pathological score of $\geqslant 10$. Of those, LVSI (100\%), nodal metastasis $(83.3 \%)$, and deep stromal invasion $(83.3 \%)$ were the three most common risk factors. Among the 18 patterns with a risk-weighted surgical-pathological score of $\geqslant 10,17(94.4 \%)$ patterns had at least two risk factors (high and/or intermediate) with two high- and two intermediate-risk factors being the most common pattern (four patterns, $n=35$ ), followed by two high- and three intermediate-risk factors ( 3 patterns, $n=28$ ). Neither of the two risk factor patterns showed a survival benefit with additional platinum-based chemotherapy and radiotherapy over radiotherapy alone (5-year DFS rate in CCRT vs RT alone, two high- and two intermediate-risk groups, $44.6 \%$ vs $50.0 \%$,
$P=0.81$; and two high- and three intermediate-risk groups, $53.7 \%$ vs $50.7 \%, P=0.73$ ).

\section{DISCUSSION}

The important findings of our study were that when early-stage cervical cancer was classified based on the extent of risk factors weighting its magnitude of significance, we were able to identify the subgroup of patients with survival outcomes comparable to advanced-stage disease. Furthermore, benefits of CCRT over RT alone among surgically treated early-stage cervical cancer showed a
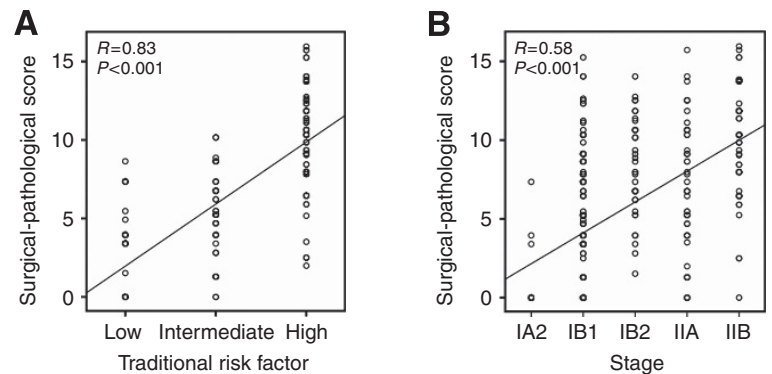

Surgical-pathological scoring (Risk-weighted)
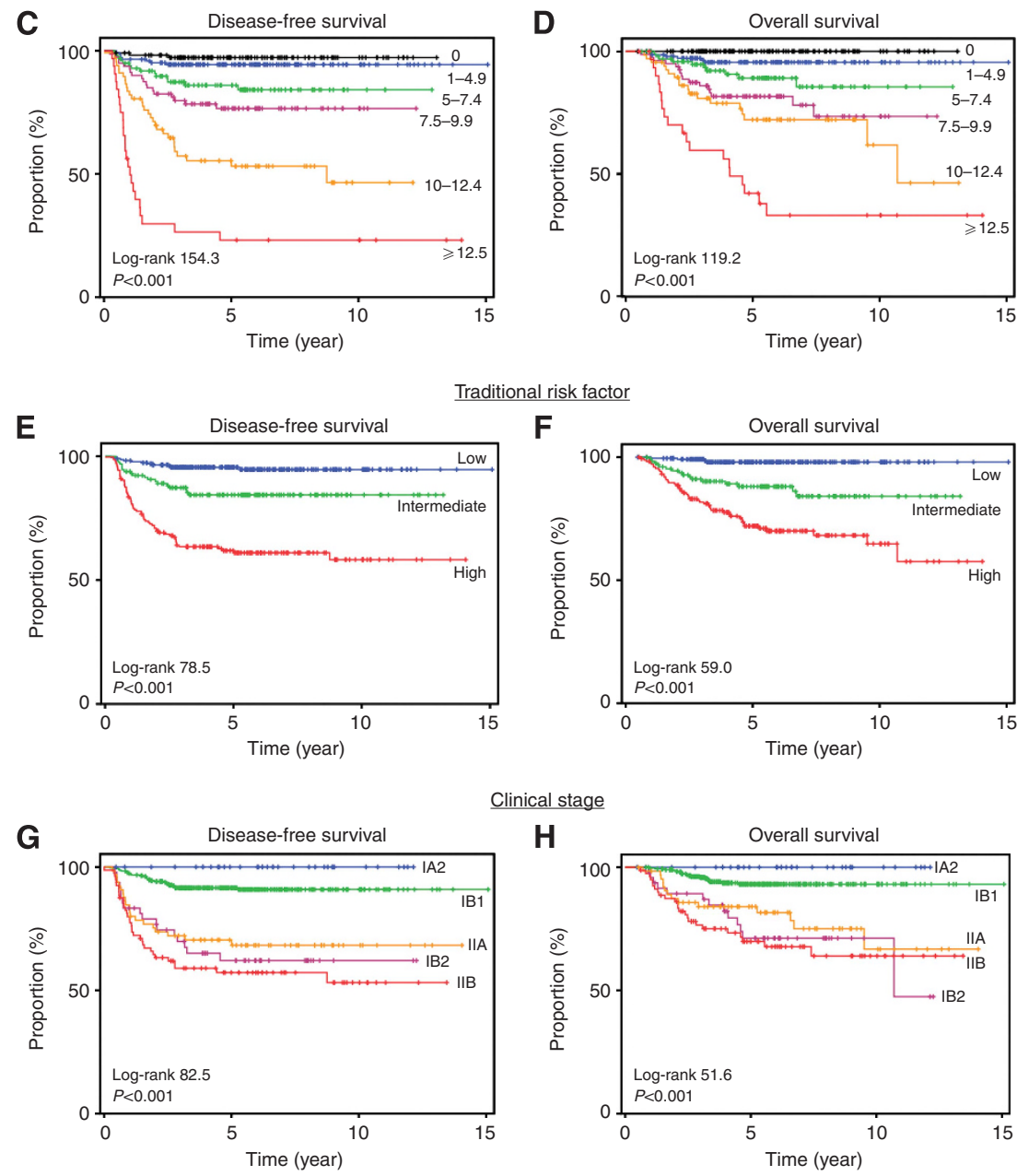

Clinical stage

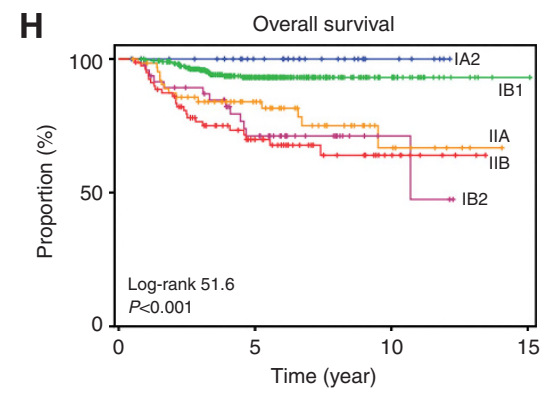

Figure 1. Risk-weighted surgical-pathological scoring and survival outcome. (A-B) Spearman's correlation coefficient between surgicalpathological scoring value (based on HR in multivariate analysis all the risk factors were entered) and (A) traditional pathological risk factor (in order of low, intermediate, and high) and (B) clinical stage (in order of IA2, IB1, IB2, IIA, and IIB). (C, D) Survival curves based on risk-weighted surgical-pathological scoring value (method 1). (E, F) Survival curves based on traditional surgical-pathological risk factor. (G, H) Survival curves based on clinical stage. Kaplan-Meier method for survival curves expressed with log-rank statistics and $P$-value. 
A

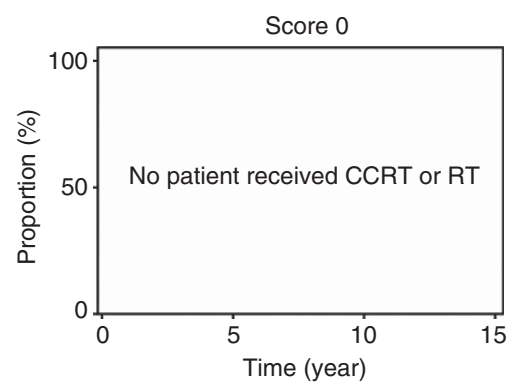

C

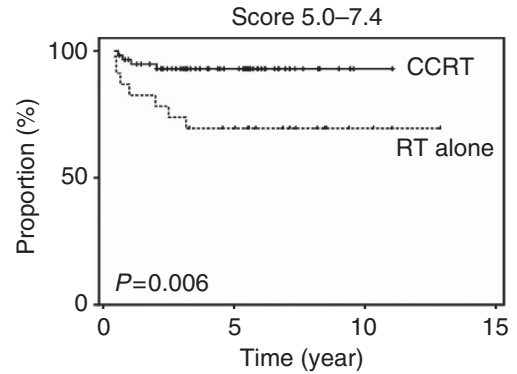

E

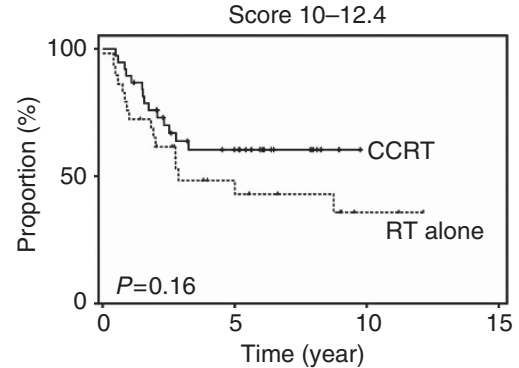

G

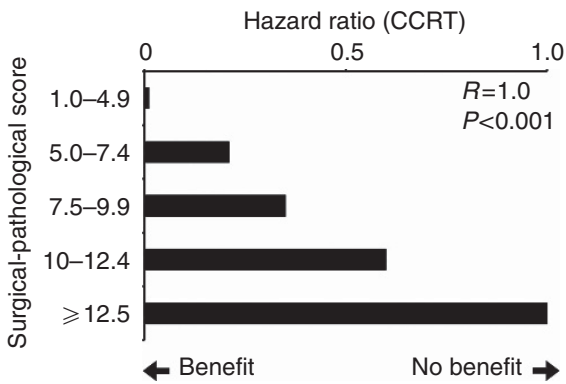

Disease-free survival
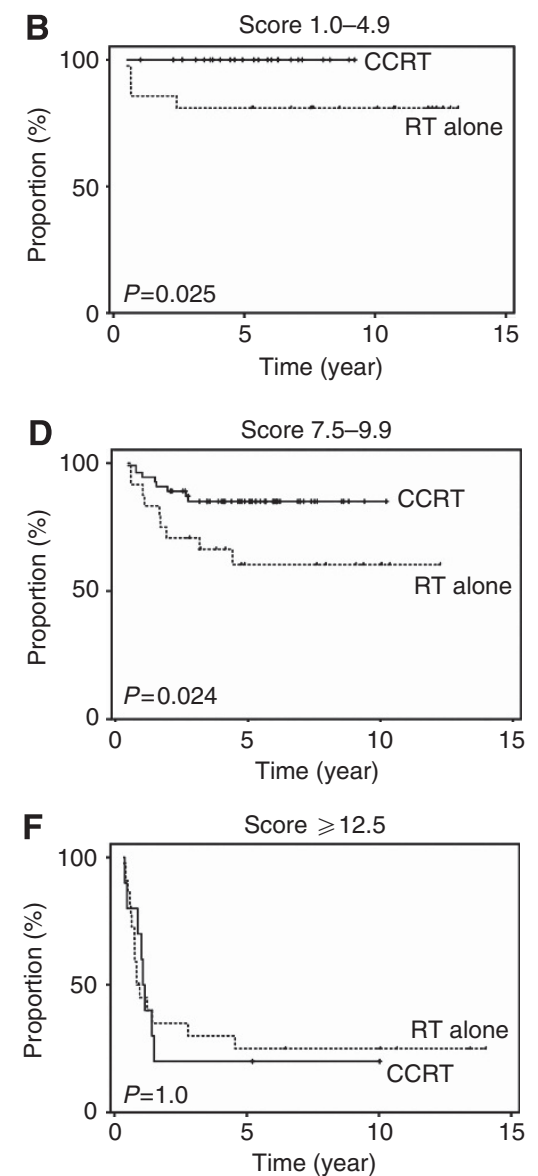

H

Overall survival

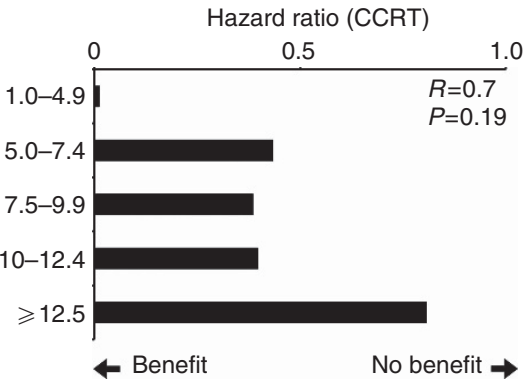

Figure 2. Surgical-pathological scoring and postoperative therapy response. (A-F) Kaplan-Meier survival curves based on risk-weighted surgicalpathological scoring value (method 1) were examined for the type of postoperative adjuvant therapy after radical hysterectomy (CCRT (black line) and RT alone (dash line)). P-value for log-rank test. (G, H) Spearman's correlation coefficient between risk-weighted surgical-pathological scoring value (method 1) and HR for CCRT in (G) DFS and (H) OS. Hazard ratio towards 0 implies benefits of CCRT over RT alone while HR towards 1 implies no benefit of CCRT over RT alone on survival outcomes.

trend towards diminishing as the tumour expresses its aggressiveness. Several key areas in this observation deserve special mention.

In our study, early FIGO stage cervical cancer patients with a surgical-pathological score $>10$ have a similar survival outcomes compared with FIGO stage III patients. Overall, 5-year DFS of FIGO stage III cervical cancer is reported as 30-50\% (Waggoner, 2003). Patients with risk-weighted surgical-pathological score of $10-12.4$ and $\geqslant 12.5$ showed 5 -year DFS of $53.3 \%$ and $23.8 \%$, respectively. In addition, 5-year OS of FIGO stage III disease is $39.7-41.5 \%$ in general population that is similar to the patients with score of $\geqslant 12.5$ in our study population (43.3\%) (Quinn et al, 2006). Our scoring method was not only correlated well to the traditional classification (Figures $1 \mathrm{~A}$ and $\mathrm{B}$ ), but also demonstrated wider ranges of survival difference among the early-stage cervical cancer patients (Figures $1 \mathrm{C}-\mathrm{H}$ ). These findings support the usefulness and durability of risk-weighted surgical-pathological scoring to enable the clinician to recognise that there is a certain population of early-stage cervical cancer patients with considerably poor survival outcomes, proposed as 'super high-risk' group for cervical cancer in our study (score $\geqslant 12.5$ ). Risk factors examined in our scoring method were similar to traditional scoring system except for histology type. Our results indicated that adenocarcinoma and adenosquamous histology remained as an independent risk factor for survival exhibiting one of the largest significances both for DFS and OS (Tables 2 and 3). As the pathophysiology and optimal management of adenocarcinoma of the cervix is not yet well understood, additional studies are warranted by others to reproduce our results (Gien et al, 2010). 
Table 5. Surgical-pathological risk factor array for risk of disease-free survival

\begin{tabular}{|c|c|c|c|c|c|c|c|c|c|c|c|}
\hline $\begin{array}{l}\text { Adeno } \\
(3.40)\end{array}$ & $\begin{array}{c}\text { Nodal } \\
\text { mets } \\
(3.88)\end{array}$ & $\begin{array}{c}\text { Parametria } \\
(1.21)\end{array}$ & $\begin{array}{c}\text { Margin }+ \\
(1.99)\end{array}$ & $\begin{array}{l}\text { LVSI } \\
(3.95)\end{array}$ & $\begin{array}{c}\text { DSI } \\
(1.29)\end{array}$ & $\begin{array}{l}\text { Large } \\
\text { tumour } \\
(2.36)\end{array}$ & $\begin{array}{l}\text { Risk group } \\
\text { (traditional) }\end{array}$ & $\begin{array}{l}\text { High } \\
\text { risk } \\
\text { (No.) }\end{array}$ & $\begin{array}{l}\text { Intermediate } \\
\text { risk (No.) }\end{array}$ & $\begin{array}{c}\text { Subject } \\
\text { no. }\end{array}$ & $\begin{array}{l}\text { Surg- } \\
\text { path } \\
\text { score }\end{array}$ \\
\hline+ & + & + & + & + & & + & $\mathrm{H}$ & 3 & 2 & 1 & 16.79 \\
\hline+ & + & + & & + & + & + & $\mathrm{H}$ & 2 & 3 & 3 & 16.09 \\
\hline+ & + & + & + & + & + & & $\mathrm{H}$ & 3 & 2 & 2 & 15.72 \\
\hline \multirow[t]{2}{*}{+} & + & & & + & + & + & $\mathrm{H}$ & 1 & 3 & 4 & 14.88 \\
\hline & + & + & + & + & + & + & $\mathrm{H}$ & 3 & 3 & 4 & 14.68 \\
\hline+ & + & + & & + & + & 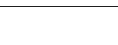 & $\mathrm{H}$ & 2 & 2 & 7 & 13.73 \\
\hline \multirow[t]{4}{*}{+} & + & & & + & - & + & $\mathrm{H}$ & 1 & 2 & 1 & 13.59 \\
\hline & + & & + & + & + & + & $\mathrm{H}$ & 2 & 3 & 1 & 13.47 \\
\hline & + & + & & + & + & + & $\mathrm{H}$ & 2 & 3 & 17 & 12.69 \\
\hline & + & + & + & + & + & & $\mathrm{H}$ & 3 & 2 & 3 & 12.32 \\
\hline+ & & + & & + & + & + & $\mathrm{H}$ & 1 & 3 & 4 & 12.21 \\
\hline \multirow[t]{2}{*}{+} & - & + & + & + & + & & $\mathrm{H}$ & 2 & 2 & 1 & 11.84 \\
\hline & + & & & + & + & + & $\mathrm{H}$ & 1 & 3 & 11 & 11.48 \\
\hline \multirow[t]{2}{*}{+} & + & & & + & . & & $\mathrm{H}$ & 1 & 1 & 2 & 11.23 \\
\hline & + & & + & + & + & & $\mathrm{H}$ & 2 & 2 & 2 & 11.11 \\
\hline \multirow[t]{3}{*}{+} & 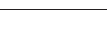 & & & + & + & + & I & 0 & 3 & 3 & 11.00 \\
\hline & + & + & & + & + & & $\mathrm{H}$ & 2 & 2 & 25 & 10.33 \\
\hline & + & & & + & 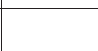 & + & $\mathrm{H}$ & 1 & 2 & 2 & 10.19 \\
\hline+ & & + & & + & + & & $\mathrm{H}$ & 1 & 2 & 4 & 9.85 \\
\hline+ & & & & + & & + & I & 0 & 2 & 1 & 9.71 \\
\hline \multirow[t]{4}{*}{+} & 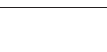 & & + & + & 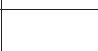 & & $\mathrm{H}$ & 1 & 1 & 1 & 9.34 \\
\hline & + & & & + & + & & $\mathrm{H}$ & 1 & 2 & 29 & 9.12 \\
\hline & + & & & + & + & . & $\mathrm{H}$ & 1 & 2 & 11 & 9.12 \\
\hline & & + & & + & + & + & $\mathrm{H}$ & 1 & 3 & 14 & 8.81 \\
\hline \multirow[t]{4}{*}{+} & & & & + & + & & I & 0 & 2 & 26 & 8.64 \\
\hline & & + & + & + & + & & $\mathrm{H}$ & 2 & 2 & 2 & 8.44 \\
\hline & + & & & + & & & $\mathrm{H}$ & 1 & 1 & 9 & 7.83 \\
\hline & & & & + & + & + & I & 0 & 3 & 21 & 7.6 \\
\hline+ & & & & + & & & 1 & 0 & 1 & 21 & 7.35 \\
\hline \multirow[t]{2}{*}{+} & & & & & + & + & I & 0 & 2 & 3 & 7.05 \\
\hline & & & & + & & + & I & 0 & 2 & 4 & 6.31 \\
\hline+ & & + & & & + & & $\mathrm{H}$ & 1 & 1 & 2 & 5.90 \\
\hline \multirow[t]{3}{*}{+} & & & & & & + & I & 0 & 1 & 1 & 5.76 \\
\hline & & & & + & + & & I & 0 & 2 & 37 & 5.24 \\
\hline & + & & & & + & & $\mathrm{H}$ & 1 & 1 & 1 & 5.17 \\
\hline \multirow[t]{4}{*}{+} & & & & & + & & I & 0 & 1 & 6 & 4.69 \\
\hline & & & + & & & + & $\mathrm{H}$ & 1 & 1 & 1 & 4.35 \\
\hline & & & & + & & & I & 0 & 1 & 42 & 3.95 \\
\hline & & & & & + & + & I & 0 & 2 & 3 & 3.65 \\
\hline \multirow[t]{5}{*}{+} & & & & & & & & 0 & 0 & 70 & 3.40 \\
\hline & & + & & & + & & $\mathrm{H}$ & 1 & 1 & 3 & 2.50 \\
\hline & & & & & & + & I & 0 & 1 & 1 & 2.36 \\
\hline & & & + & & & & $\mathrm{H}$ & 1 & 0 & 1 & 1.99 \\
\hline & & & & & + & & I & 0 & 1 & 18 & 1.29 \\
\hline
\end{tabular}


Surprisingly, the larger the risk-weighted surgical-pathological score was, the lower the benefit of additional platinum-based chemotherapy during radiotherapy after radical hysterectomy was (Figures $2 \mathrm{G}-\mathrm{H}$ ). This finding was clearly evident in the group with scores greater than 10 . It is speculated that these patients with score $\geqslant 10$ likely have occult distant metastases that could not be sterilised by additional platinum-based chemotherapy. As the concurrent administration of cisplatin-based chemotherapy during radiotherapy is a standard practice for postoperative adjuvant therapy (high-risk or intermediate-risk groups), additional therapeutic approaches are needed to improve the survival outcome in this particular population of 'super high-risk' group. Lymphovascular space invasion, adenocarcinoma or adenosquamous, and lymph nodal metastasis were the top three risk factors with large HR associated with decreased DFS and OS in our study. Therefore, targeting these risk factors will be an attractive therapeutic approach. Recent studies have demonstrated that increased LVSI is strongly associated with vascular endothelial growth factor (VEGF) pathway in solid tumours (Lee et al, 2002; Spannuth et al, 2008; Botting et al, 2010). In addition, LVSI is significantly correlated with nodal metastasis (Juretzka et al, 2004; Milam et al, 2007). Therefore, it may be reasonable to consider administering anti-VEGF agents to 'super high-risk' tumours exhibiting LVSI (Monk et al, 2010). In a recent review, providing additional paclitaxel to treatment, extending the chemotherapy course, and selecting a biological target such as anti-VEGF or anti-epidermal growth factor receptor agents are suggested to have a potential role in the management of adenocarcinoma of the cervix (Gien et al, 2010). Finally, as the survival outcomes of patients with riskweighted surgical score $\geqslant 12.5$ is similar to advanced-stage disease, the indication and efficacy of consolidation therapy after postoperative adjuvant treatment needs to be considered in the future (Vrdoljak et al, 2006; Zhang et al, 2010; Choi et al, 2011).

The role of multiple risk factors in risk-weighted surgicalpathological scoring merits further discussion. In a review of literature, analyses of pooled data from GOG/SWOG/RTOG trials evaluating tumours with high-risk factors based on the presence of additional intermediate-risk factors (tumour size) showed that adding platinum-based chemotherapy to radiotherapy after radical hysterectomy for stage IA2-IIA cervical cancer significantly improved survival outcome if the tumour was $>2 \mathrm{~cm}$ (5-year survival rate, $19 \%$ absolute improvement) (Monk et al, 2005). In addition, the results of a phase III randomised trial that enrolled node-negative stage IB cervical cancer patients exhibiting multiple intermediate-risk factors showed that pelvic radiotherapy after radical hysterectomy significantly reduced risk of recurrence when compared with the treatment arm without additional radiotherapy (Rotman et al, 2006). In our results shown in Table 5, a considerable proportion of cervical cancer patients exhibited multiple high-risk factors (12.6\%) or high-risk factor with multiple intermediate-risk factors (27.4\%), and these multiple high-risk factor tumours did not show benefits of CCRT over RT alone. As cervical cancer patients with multiple high-risk factors are not rare and such patients have not yet been fully evaluated for the role of additional platinum-based chemotherapy with radiotherapy, further prospective cohort studies are merited.

The strength of our study is that the sample size is adequate for the analysis and that treatment plan and pathology evaluation are similar between the two institutions that participated in the study. A potential weakness of the study is that it is retrospective in nature, and thus factors such as treatment algorithms, including various surgical techniques, chemotherapy protocols, and radiation approaches, may be confounded. Another limitation is that we do not have data for how patients were allocated to treatment types (selection bias).

In conclusion, evaluation of surgically treated cervical cancer by number of tumour risk factors with its magnitude of significance for survival demonstrated the ability to understand the aggressiveness of tumour biology. This approach merits further investigation especially in its implication to postoperative adjuvant therapy.

\section{ACKNOWLEDGEMENTS}

This work was supported in part by Grant-in-aid for General Scientific Research No 23592446 from the Ministry of Education, Culture, Sports, Science, and Technology of Japan.

\section{CONFLICT OF INTEREST}

The author declare no conflict of interest.

\section{REFERENCES}

Botting SK, Fouad H, Elwell K, Rampy BA, Salama SA, Freeman DH, Diaz-Arrastia CR (2010) Prognostic significance of peritumoral lymphatic vessel density and vascular endothelial growth factor receptor 3 in invasive squamous cell cervical cancer. Transl Oncol 3: 170-175.

Choi CH, Lee YY, Kim MK, Kim TJ, Lee JW, Nam HR, Huh SJ, Lee JH, Bae DS, Kim BG (2011) A matched-case comparison to explore the role of consolidation chemotherapy after concurrent chemoradiation in cervical cancer. Int J Radiat Oncol Biol Phys 81: 1252-1257.

Delgado G, Bundy B, Zaino R, Sevin BU, Creasman WT, Major F (1990) Prospective surgical-pathological study of disease-free interval in patients with stage IB squamous cell carcinoma of the cervix: a Gynecologic Oncology Group study. Gynecol Oncol 38: 352-357.

Gien LT, Beauchemin MC, Thomas G (2010) Adenocarcinoma: a unique cervical cancer. Gynecol Oncol 116: 140-146.

Havrilesky LJ, Leath CA, Huh W, Calingaert B, Bentley RC, Soper JT, Alvarez Secord A (2004) Radical hysterectomy and pelvic lymphadenectomy for stage IB2 cervical cancer. Gynecol Oncol 93: 429-434.

Jemal A, Bray F, Center MM, Ferlay J, Ward E, Forman D (2011) Global cancer statistics. CA Cancer J Clin 61: 69-90.

Juretzka MM, Jensen KC, Longacre TA, Teng NN, Husain A (2004) Detection of pelvic lymph node micrometastasis in stage IA2-IB2 cervical cancer by immunohistochemical analysis. Gynecol Oncol 93: 107-111.

Lee JS, Kim HS, Jung JJ, Lee MC, Park CS (2002) Expression of vascular endothelial growth factor in adenocarcinomas of the uterine cervix and its relation to angiogenesis and p53 and c-erbB-2 protein expression. Gynecol Oncol 85: 469-475.

Mabuchi S, Isohashi F, Maruoka S, Hisamatsu T, Takiuchi T, Yoshioka Y, Kimura T (2012) Post-treatment follow-up procedures in cervical cancer patients previously treated with radiotherapy. Arch Gynecol Obstet 286: 179-185.

Mabuchi S, Isohashi F, Yoshioka Y, Temma K, Takeda T, Yamamoto T, Enomoto T, Morishige K, Inoue T, Kimura T (2010) Prognostic factors for survival in patients with recurrent cervical cancer previously treated with radiotherapy. Int J Gynecol Cancer 20: 834-840.

Mabuchi S, Kimura T (2011) Nedaplatin: a radiosensitizing agent for patients with cervical cancer. Chemother Res Pract 2011: 963159.

Mabuchi S, Morishige K, Isohashi F, Yoshioka Y, Takeda T, Yamamoto T, Yoshino K, Enomoto T, Inoue T, Kimura T (2009) Postoperative concurrent nedaplatin-based chemoradiotherapy improves survival in early-stage cervical cancer patients with adverse risk factors. Gynecol Oncol 115: $482-487$.

Mabuchi S, Okazawa M, Isohashi F, Matsuo K, Ohta Y, Suzuki O, Yoshioka Y, Enomoto T, Kamiura S, Kimura T (2011a) Radical hysterectomy with adjuvant radiotherapy versus definitive radiotherapy alone for FIGO stage IIB cervical cancer. Gynecol Oncol 123: 241-247.

Mabuchi S, Okazawa M, Isohashi F, Ohta Y, Maruoka S, Yoshioka Y, Enomoto T, Morishige K, Kamiura S, Kimura T (2011b) Postoperative whole pelvic radiotherapy plus concurrent chemotherapy versus extended-field irradiation for early-stage cervical cancer patients with multiple pelvic lymph node metastases. Gynecol Oncol 120: 94-100. 
Milam MR, Frumovitz M, dos Reis R, Broaddus RR, Bassett Jr RL, Ramirez PT (2007) Preoperative lymph-vascular space invasion is associated with nodal metastases in women with early-stage cervical cancer. Gynecol Oncol 106: $12-15$.

Monk BJ, Wang J, Im S, Stock RJ, Peters 3rd WA, Liu PY, Barrett 2nd RJ, Berek JS, Souhami L, Grigsby PW, Gordon Jr W, Alberts DS. Gynecologic Oncology Group; Southwest Oncology Group; Radiation Therapy Oncology Group. (2005) Rethinking the use of radiation and chemotherapy after radical hysterectomy: a clinical-pathologic analysis of a Gynecologic Oncology Group/Southwest Oncology Group/Radiation Therapy Oncology Group trial. Gynecol Oncol 96: 721-728.

Monk BJ, Willmott LJ, Sumner DA (2010) Anti-angiogenesis agents in metastatic or recurrent cervical cancer. Gynecol Oncol 116: 181-186.

Okazawa M, Mabuchi S, Isohashi F, Suzuki O, Ohta Y, Fujita M, Yoshino K, Enomoto T, Kamiura S, Kimura T (2012) The prognostic significance of multiple pelvic node metastases in cervical cancer patients treated with radical hysterectomy plus adjuvant chemoradiotherapy. Int J Gynecol Cancer 22: 490-497.

Peters 3rd WA, Liu PY, Barrett 2nd RJ, Stock RJ, Monk BJ, Berek JS, Souhami L, Grigsby P, Gordon Jr. W, Alberts DS (2000) Concurrent chemotherapy and pelvic radiation therapy compared with pelvic radiation therapy alone as adjuvant therapy after radical surgery in high-risk early-stage cancer of the cervix. J Clin Oncol 18: 1606-1613.

Quinn MA, Benedet JL, Odicino F, Maisonneuve P, Beller U, Creasman WT, Heintz AP, Ngan HY, Pecorelli S (2006) Carcinoma of the cervix uteri. FIGO 26th Annual Report on the Results of Treatment in Gynecological Cancer. Int J Gynaecol Obstet 95(Suppl 1): S43-103.

Rotman M, Sedlis A, Piedmonte MR, Bundy B, Lentz SS, Muderspach LI, Zaino RJ (2006) A phase III randomized trial of postoperative pelvic irradiation in Stage IB cervical carcinoma with poor prognostic features: follow-up of a gynecologic oncology group study. Int J Radiat Oncol Biol Phys 65: 169-176.

Sedlis A, Bundy BN, Rotman MZ, Lentz SS, Muderspach LI, Zaino RJ (1999) A randomized trial of pelvic radiation therapy versus no further therapy in selected patients with stage IB carcinoma of the cervix after radical hysterectomy and pelvic lymphadenectomy: A Gynecologic Oncology Group Study. Gynecol Oncol 73: 177-183.

Spannuth WA, Sood AK, Coleman RL (2008) Angiogenesis as a strategic target for ovarian cancer therapy. Nat Clin Pract Oncol 5: 194-204.

Vrdoljak E, Omrcen T, Novakovic ZS, Jelavic TB, Prskalo T, Hrepic D, Hamm W (2006) Concomitant chemobrachyradiotherapy with ifosfamide and cisplatin followed by consolidation chemotherapy for women with locally advanced carcinoma of the uterine cervix-final results of a prospective phase II-study. Gynecol Oncol 103: 494-499.

Waggoner SE (2003) Cervical cancer. Lancet 361: 2217-2225.

WHO. In: Tavassoli FA, Stratton MR (eds) (2002) Tumors of the uterine cervix. In WHO classification of tumors: pathology and genetics of tumors of the breast and female genital organs. pp 259-289. IARC Press: Lyon (2002).

Zhang MQ, Liu SP, Wang XE (2010) Concurrent chemoradiotherapy with paclitaxel and nedaplatin followed by consolidation chemotherapy in locally advanced squamous cell carcinoma of the uterine cervix: preliminary results of a phase II study. Int J Radiat Oncol Biol Phys 78: $821-827$.

This work is published under the standard license to publish agreement. After 12 months the work will become freely available and the license terms will switch to a Creative Commons AttributionNonCommercial-Share Alike 3.0 Unported License.

Supplementary Information accompanies this paper on British Journal of Cancer website (http://www.nature.com/bjc) 